\section{State of the Art Review}

\section{Check for updates}

\section{OPEN ACCESS}

Received: Jan 25, 2021

Accepted: Jan 29, 2021

Correspondence to

Boyoung Joung, MD, PhD

Division of Cardiology, Department of Internal

Medicine, Severance Cardiovascular Hospital,

Yonsei University College of Medicine, 50-1,

Yonsei-ro, Seodaemun-gu, Seoul 03722, Korea.

E-mail: cby6908@yuhs.ac

*Daehoon Kim and Pil-Sung Yang contributed equally to this work.

\section{Copyright (c) 2021. The Korean Society of Cardiology \\ This is an Open Access article distributed under the terms of the Creative Commons Attribution Non-Commercial License (https:// creativecommons.org/licenses/by-nc/4.0) which permits unrestricted noncommercial use, distribution, and reproduction in any medium, provided the original work is properly cited.}

\section{ORCID iDs}

Daehoon Kim (1D)

https://orcid.org/0000-0002-9736-450X

Pil-Sung Yang (D)

https://orcid.org/0000-0002-6552-1742

Boyoung Joung (D)

https://orcid.org/0000-0001-9036-7225

Funding

This study was supported by a research grant from the Korean Healthcare Technology R\&D project funded by the Ministry of Health \& Welfare (HI15C1200, HC19C0130).

\section{Conflict of Interest}

The authors have no financial conflicts of interest.

\section{Prevention of Dementia in Patients with Atrial Fibrillation}

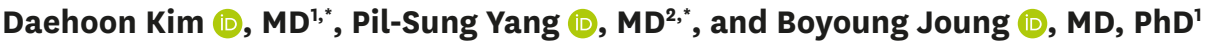 \\ 'Division of Cardiology, Department of Internal Medicine, Severance Cardiovascular Hospital, Yonsei \\ University College of Medicine, Seoul, Korea \\ ${ }^{2}$ Department of Cardiology, CHA Bundang Medical Center, CHA University, Seongnam, Korea
}

\section{AUTHOR'S SUMMARY}

Atrial fibrillation (AF) has been associated with an increased risk of dementia. Although there does not appear to be solid evidence that any specific treatment prevents or delays AF-associated cognitive decline, evidence is accumulating regarding the possible treatment strategies for preventing dementia. In this review, we summarize the evidence linking AF to dementia and critically appraise the proposed treatment strategies.

\section{ABSTRACT}

Atrial fibrillation $(\mathrm{AF})$ is the most common form of arrhythmia in the elderly population and increases stroke risk by a factor of 4 - to 5 -fold. There is increasing evidence to suggest that incident AF may contribute to the development of dementia, independent of overt stroke. In particular, relatively younger patients with $\mathrm{AF}$ are more prone to dementia development than older patients with AF. Evidence is accumulating regarding the possible treatment strategies for preventing dementia in patients with AF. Oral anticoagulation may be effective for reducing the risk of dementia, even in patients with low stroke risks. Among oral anticoagulants, the use of non-vitamin $\mathrm{K}$ antagonists have been associated with a considerably decreased risk of dementia than warfarin. Moreover, successful catheter ablation for AF has also been associated with decreased dementia risk compared to medical therapy, suggesting that restoration of sinus rhythm, and not the ablation procedure itself, as the important mechanism in the prevention of AF-associated dementia. Among midlife patients with AF, there appeared to be a U-shaped association of blood pressure (BP) and a linear association of hypertension with dementia risk. A BP of 120 to $129 / 80$ to $84 \mathrm{mmHg}$ has been identified as the optimal range. Finally, integrated management of AF was associated with a reduced risk of dementia in AF patients.

Keywords: Atrial fibrillation; Dementia; Anticoagulants; Catheter ablation; Risk factors

\section{INTRODUCTION}

Atrial fibrillation $(\mathrm{AF})$ is the most common form of sustained cardiac arrhythmia in the elderly population. ${ }^{122} \mathrm{AF}$ increases the risk of mortality and morbidity resulting from stroke, congestive heart failure, and impaired quality of life, explaining its enormous socioeconomic 
Data Sharing Statement

The data generated in this study is available from the corresponding author(s) upon reasonable request.

\section{Author Contributions}

Data curation: Yang PS; Formal analysis:

Yang PS; Investigation: Kim D, Joung B;

Methodology: Kim D, Yang PS; Resources: Kim D; Supervision: Yang PS, Joung B; Validation: Joung B; Writing - original draft: Kim D, Joung B; Writing - review \& editing: Kim D, Yang PS, Joung B. and healthcare implications. ${ }^{1-3)}$ The age distribution of AF among populations in the developed countries is predicted to shift in the coming years, with an expected increase in prevalence among the elderly. The fact that AF prevalence has progressively risen 2.10-fold over the past 10 years in Korea, with an increase to $8.15 \%$ in patients $\geq 80$ years of age, supports this predicted progression. ${ }^{2)}$ Globally, 40 million people are living with dementia, and this number is expected to increase with a rising aged population. ${ }^{4}$ Although the pathophysiological mechanisms of dementia are largely unknown, evidence is accumulating that AF may contribute to the development of cognitive dysfunction and dementia, even in patients without overt stroke.-8) In this review, we summarize the evidence linking AF to dementia and critically appraise potential treatment strategies for preventing AF-associated cognitive decline.

\section{ATRIAL FIBRILLATION AND DEMENTIA}

\section{Atrial fibrillation increases the risk of dementia}

The Rotterdam study demonstrated that cognitive dysfunction was approximately twice as common in subjects with AF than in those without. ${ }^{5}$ However, the cross-sectional design of that study precluded definitive conclusions regarding a causal relationship. Since then, several longitudinal studies have investigated the association between AF and incidental dementia, with inconsistent results. Some studies have found that AF is associated with an increased risk of cognitive decline or dementia. ${ }^{6-8)}$ Others have shown no association. ${ }^{9110}$

Kim et al. ${ }^{11)}$ investigated the association of incidental $\mathrm{AF}$ with the development of incidental dementia in 262,611 dementia- and stroke-free participants aged $\geq 60$ years, using the Korea National Health Insurance Service (NHIS)-Senior cohort. The incidence of dementia was 4.1 and 2.7 per 100 person-years in the incidental AF and propensity score-matched AF-free groups, respectively. Incidental AF, being analysed as a time-varying factor to avoid immortal time bias, is associated with higher risks of dementia with a hazard ratio (HR) of 1.52, even after additionally censoring participants at the time of an incidence of stroke with a HR of 1.27 (Figure 1). Incidental AF increased the risk of both Alzheimer's disease and vascular dementia.
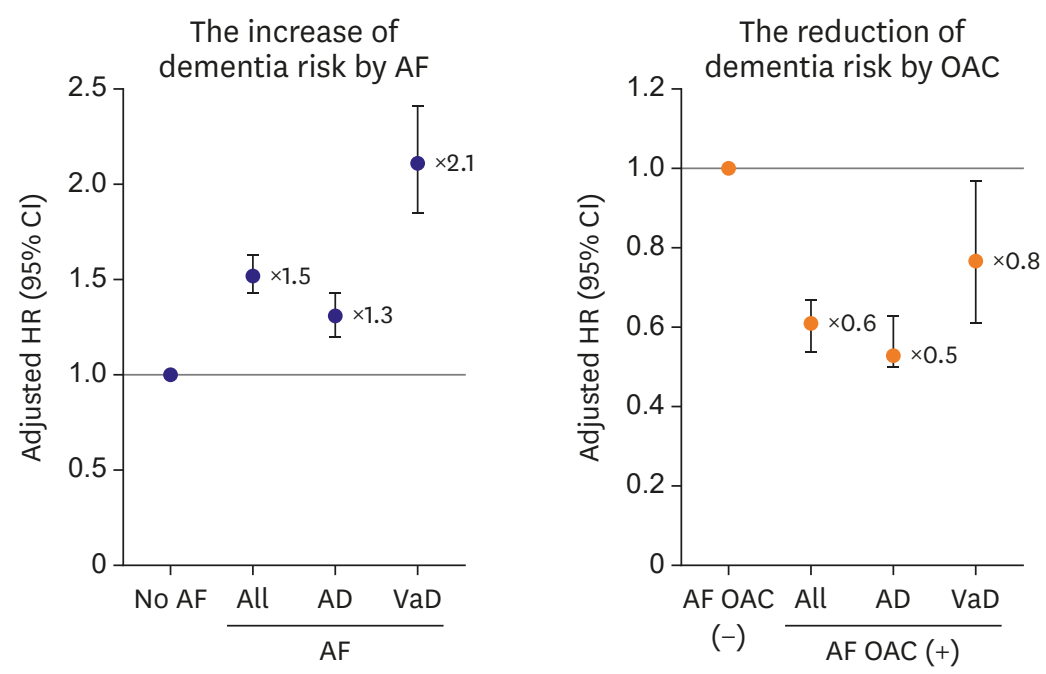

Figure 1. Risk of dementia according to atrial fibrillation in the study population (left). Effects of OAC on the risk of dementia in patients with atrial fibrillation (right). Figure courtesy of Kim et al. ${ }^{11)}$ $\mathrm{AD}=$ Alzheimer's disease, $\mathrm{AF}=$ atrial fibrillation; $\mathrm{Cl}$ = confidence interval; $\mathrm{HR}$ = hazard ratio; OAC = oral anticoagulant, $\mathrm{VaD}=$ vascular dementia. 


\section{Atrial fibrillation and early-onset dementia}

In contrast to the aged population, early-onset dementia, with onset at age $<65$ years, is a devastating condition affecting patients who still have active socioeconomic involvements. The association between AF and dementia is not well identified in different age subgroups. Kim et al. investigated the associations between incidental AF and the risk of early-onset dementia / late-onset dementia (onset at age $\geq 65$ years) in 428,262 participants without a history of dementia or stroke in the Korea NHIS-Health Screening cohort. ${ }^{12}$ Incidental AF was associated with an increased risk of both early- (HR, 2.91; 95\% confidence interval [CI], 1.93-4.41) and late-onset dementia ( $\mathrm{HR}, 1.67$; 95\% CI, 1.49-1.87), independently of a clinical stroke. Younger patients with AF were more prone to the development of dementia than older patients with $\mathrm{AF}$ ( $\mathrm{p}$ for trend $<0.001$ ) (Figure 2).

\section{HOW TO PREVENT DEMENTIA IN PATIENTS WITH ATRIAL FIBRILLATION}

\section{Lowering the risk of dementia with oral anticoagulants}

Evidence is accumulating that the pathogenesis linking AF to dementia is likely multifactorial. However, cerebral infarction including silent stroke plays a central role. ${ }^{13)}$ There is growing evidence to suggest that oral anticoagulants (OACs) are effective in lowering the risk of AF-related dementia, although preventing dementia is not the primary focus of $\mathrm{OAC}$ treatment in patients with $\mathrm{AF} .{ }^{1114115)} \mathrm{Kim}$ et al. reported that OACs had a preventive effect on dementia with an HR of 0.61 among patients with incidental AF (Figure 1). A nationwide Swedish cohort study by Friberg and Rosenqvist ${ }^{14)}$ found that patients with AF who received OAC treatment had a $29 \%$ lower risk of dementia than those with AF who were not prescribed OACs (HR, 0.71; 95\% CI, 0.68-0.74). In the study, the benefit of OAC treatment appeared to be more prominent as it had been initiated since the initial diagnosis of AF, suggesting a dose-response relationship between time without $\mathrm{OAC}$ and the development of dementia. The same authors also reported that OAC use in AF patients aged $>65$ years was associated with a lower risk of dementia irrespective of their stroke risk score, suggesting the benefit of OAC even in patients with low risks. ${ }^{15}$
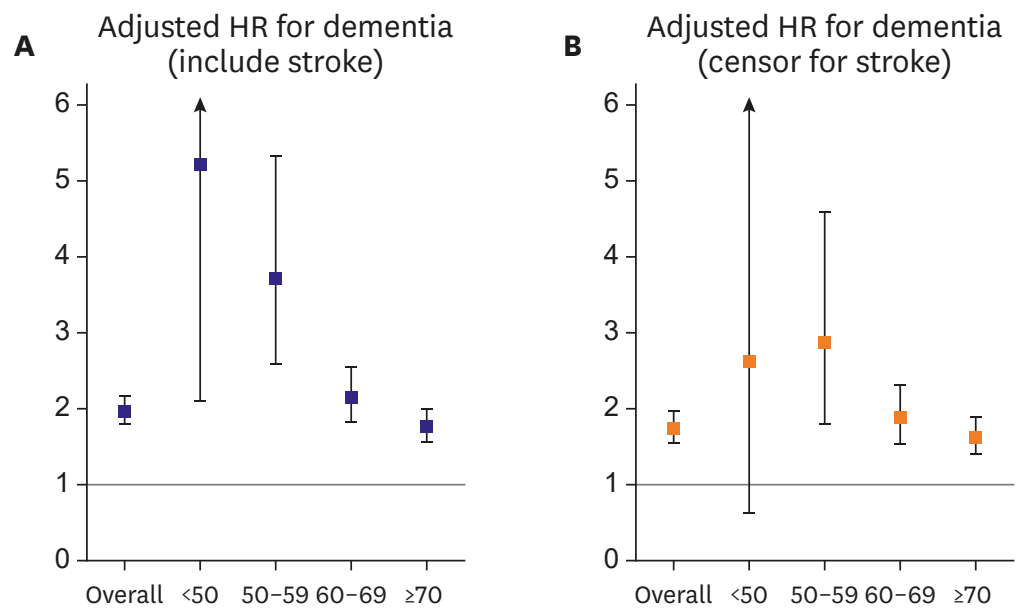

Figure 2. HRs for dementia per decade of age in the presence of AF. (A) Including stroke during the follow-up. (B) Excluding stroke during the follow-up. The horizontal line (at HR 1) indicates no difference in HRs between the AF and non-AF groups. Figure courtesy of Kim et al. ${ }^{12}$ $\mathrm{AF}=$ atrial fibrillation; $\mathrm{HR}=$ hazard ratio. 


\section{Greater benefit of non-vitamin $\mathrm{K}$ antagonist oral anticoagulants than warfarin}

In $\mathrm{AF}$ patients receiving warfarin, a lower time-in-therapeutic range has been associated with a higher risk of dementia. ${ }^{1617)}$ There is a concern regarding a higher risk of microbleeds in patients treated with warfarin, especially where the anticoagulation control is suboptimal. Microbleeds may cause chronic cerebral injuries and eventually lead to cognitive decline. ${ }^{18)}$ Currently, there is no available randomized data on the efficacy of different OACs in preventing dementia in individuals with AF. A meta-analysis of 4 randomized trials comparing non-vitamin $\mathrm{K}$ antagonist oral anticoagulants (NOACs) to warfarin demonstrated that NOACs were associated with a significant risk reduction in terms of overall stroke and systemic embolism, ${ }^{19)}$ with a greater effect observed in Asians compared to non-Asians. ${ }^{20)}$ Since NOACs have more predictable pharmacokinetics, the therapeutic levels could be more steady. As such, it has been hypothesized that NOACs could further reduce the risk of dementia compared to warfarin. The risk of dementia according to oral anticoagulant regimens from Asian, European, and North American populations is presented in Figure 3. Two US cohort studies supported the hypothesis of a lower incidence of dementia in NOAC users compared with warfarin users. ${ }^{21222}$ In contrast, nationwide Swedish and Danish cohort studies found similar incidences of dementia when comparing warfarin and NOAC usage in their patients. ${ }^{14 / 23)}$ Large longitudinal studies with a longer follow-up time are needed to clarify the effect of NOACs on cognitive functions. Currently, several randomized-controlled clinical trials focusing on cognitive outcomes in patients with $\mathrm{AF}$ are in progress. ${ }^{24}$ Kim et al. ${ }^{25}$ enrolled 52,888 new OAC users with AF (aged $\geq 60$ years, 31,211 NOAC users and 21,677 warfarin users) from the Korean NHIS database. Relative to propensity-matched warfarin users, NOAC users tended to have a lower risk of dementia (HR, 0.78; 95\% CI, 0.69-0.90) (Figure 3). When comparing individual NOACs with warfarin, all the three NOACs (apixaban, dabigatran, and rivaroxaban) were associated with a lower dementia risk. The associations were more prominent among NOAC users on standard dosages.

\section{Catheter ablation for atrial fibrillation can reduce the risk of dementia}

Compared to antiarrhythmic drug therapy, catheter ablation for AF reduces the number of acute episodes and prolongs the duration of sinus rhythm, thereby improving the quality of

\begin{tabular}{|c|c|c|c|c|c|c|c|c|c|}
\hline \multirow{2}{*}{ Database } & \multirow{2}{*}{ Patient group } & \multirow{2}{*}{ Method } & \multicolumn{2}{|c|}{ NOAC } & \multicolumn{2}{|c|}{ Warfarin } & \multirow{2}{*}{$\mathrm{HR}(95 \% \mathrm{Cl})$} & \multicolumn{2}{|c|}{ Dementia risk } \\
\hline & & & Total & Incidence & Total & Incidence & & Favors NOAC & Favors warfarin \\
\hline \multirow[t]{2}{*}{ Korean NHIS ${ }^{25)}$} & Overall & PSM & 10,193 & 3.49 & 10,193 & 5.01 & $0.78(0.68-0.90)$ & け & \\
\hline & & $\mathrm{IPW}^{*}$ & 28,693 & 3.70 & 24,553 & 3.75 & $0.85(0.77-0.93)$ & 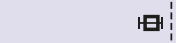 & \\
\hline \multirow[t]{3}{*}{ Danish national registers ${ }^{23)}$} & Age $60-69$ years & & 6,846 & 0.11 & 4,332 & 0.12 & $0.92(0.48-1.76)$ & $\longmapsto \theta_{1}^{\prime}$ & 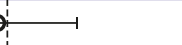 \\
\hline & Age $70-79$ years & $\mathrm{IPW}^{*}$ & 8,126 & 0.64 & 5,387 & 0.78 & $0.86(0.68-1.09)$ & •O & 4 \\
\hline & Age $\geq 80$ years & & 6,339 & 2.16 & 3,653 & 1.70 & $1.31(1.07-1.59)$ & & :- \\
\hline \multirow[t]{2}{*}{ Swedish national registers ${ }^{14 / 15}$} & Overall & PSM & 7,349 & + & 7,349 & + & $0.97(0.67-1.40)$ & $\longmapsto$ & $\dot{\leftrightarrow}$ \\
\hline & Low risk ${ }^{\ddagger}$ & PSM & 2,528 & 0.42 & 2,528 & 0.74 & $0.47(0.18-1.22)$ & $\diamond$ & : \\
\hline \multirow{3}{*}{$\begin{array}{l}\text { US MarketScan } \\
+ \text { Optum Clinformatics }{ }^{21)}\end{array}$} & Dabigatran users & & 45,439 & 1.96 & 45,439 & 2.45 & $0.79(0.71-0.88)$ & ம) & \\
\hline & Rivaroxaban users & PSM & 60,178 & 2.22 & 60,178 & 2.73 & $0.79(0.63-0.99)$ & 1 & \\
\hline & Apixaban users & & 30,218 & 2.75 & 30,218 & 3.26 & $0.73(0.52-1.02)$ & 0 & \\
\hline
\end{tabular}

Figure 3. Risk of dementia according to oral anticoagulant regimens from Asian, European, and North American populations. Incidences were presented as rates per 100 person-years. Figure courtesy by Kim et al. ${ }^{25)}$

Incidences were presented as rates per 100 person-years.

$\mathrm{Cl}=$ confidence interval; $\mathrm{HR}$ = hazard ratio; IPW = inverse probability of treatment weighting; NHIS = National Health Insurance Service; NOAC = non-vitamin $\mathrm{K}$ antagonist oral anticoagulant; PSM = propensity score matching.

${ }^{*}$ Incidences and HRs were propensity-weighted; ' Incidences were not presented in the article; ${ }^{\ddagger} \mathrm{CHA}_{2} \mathrm{DS}_{2}-\mathrm{VASC}^{\dagger} 1$ (no points for female sex). 
life. ${ }^{2627)}$ Two recent studies demonstrated that cognitive function improved following catheter ablation. ${ }^{2829)}$ Conversely, AF ablation has been associated with declining cognitive function and acute brain lesions. ${ }^{30-32)}$ However, a direct association between a silent cerebral embolism and decline in neurocognitive function is yet to be proven. ${ }^{33}$ The clinical significance of such asymptomatic cerebral embolic lesions is not known, and many will likely resolve to the point of being undetectable after weeks or months. These silent cerebral emboli are required to be distinguished from covert embolic strokes consequent to chronic AF.

Using the Korean NHIS database, Kim et al. ${ }^{34)}$ compared the risk of dementia between 9,119 patients undergoing ablation and 17,978 patients managed using medical therapy (antiarrhythmic or rate control drugs). During a median follow-up of 52 months, compared to patients on medical therapy, ablated patients showed a lower incidence and a reduced risk of dementia overall (8.1 and 5.6 per 1,000 person-years, respectively; HR, 0.73; 95\% CI, 0.58-0.93) (Figure 4). The association between ablation and a reduced dementia risk was consistently observed even after additionally censoring for incidental strokes (HR, 0.76; 95\% CI, 0.61-0.95). The protective effect of ablation against dementia was strongly observed for the ablation success group, in whom the sinus rhythm was likely maintained. The authors inferred that the restoration of sinus rhythm, and not the ablation procedure itself, was the important mechanism. However, in the claims-based database the study used, repeated ablation, cardioversion, and antiarrhythmic drug use were the only indices of post-ablation $\mathrm{AF}$ recurrences; thus, the actual burden of AF was unknown.

\section{RISK FACTOR CONTROL AND DEMENTIA}

\section{Risk factors and brain}

$\mathrm{AF}$ is highly prevalent. A prevalence of $1-2 \%$ is found in the general population but this increases up to $10 \%$ in elderly individuals aged over 80 years. ${ }^{2)}$ Dementia is also increasingly

\section{Association between catheter ablation and dementia in AF}
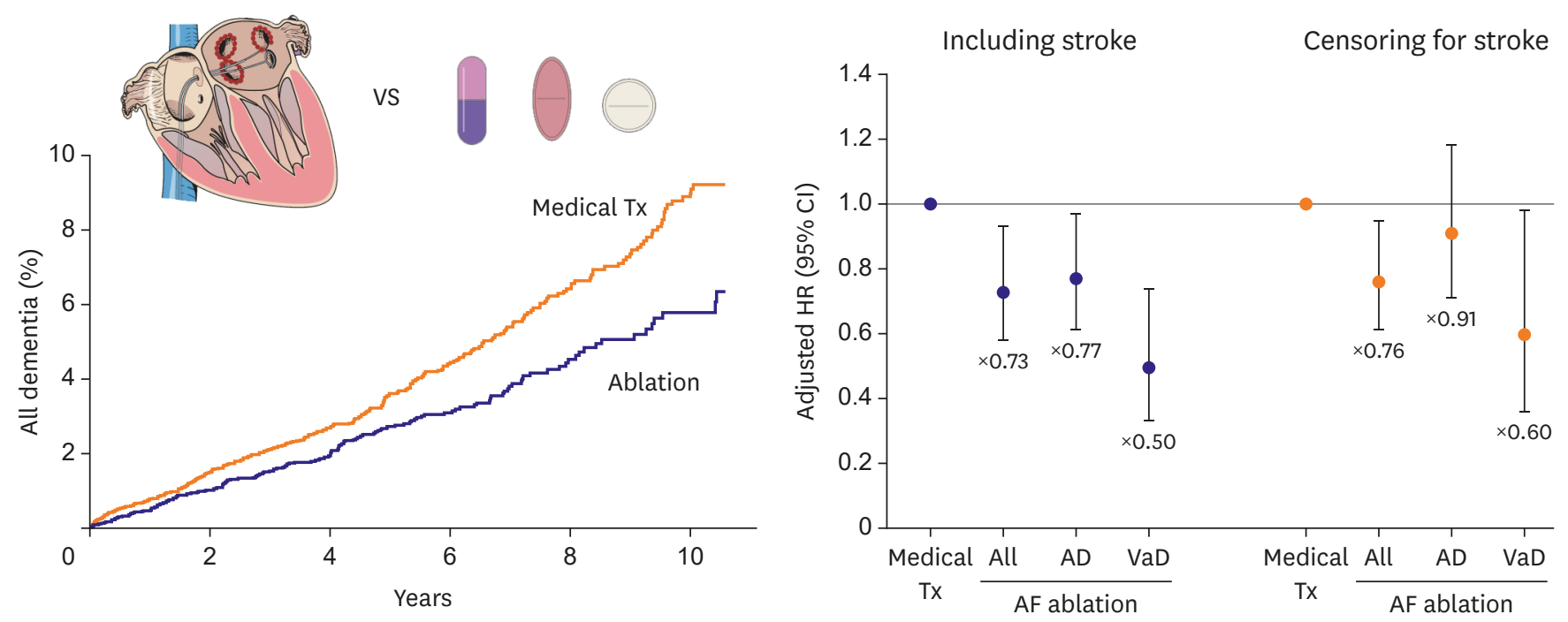

Figure 4. Cumulative incidence curves of overall dementia in propensity-matched patients undergoing ablation or medical therapy (left). Risk of dementia in propensity score-matched patients undergoing ablation or medical therapy (right). Figure courtesy of Kim et al. ${ }^{34)}$ $\mathrm{AD}=$ Alzheimer's disease, $\mathrm{AF}=$ atrial fibrillation; $\mathrm{Tx}=$ treatment; $\mathrm{VaD}=$ vascular dementia. 
common in the elderly. This poses a major global challenge for healthcare and social care in ageing populations. ${ }^{35}$ The relationship between $\mathrm{AF}$ and dementia may also be explained by common vascular risk factors which increase with advancing age. ${ }^{36)}$ Cox et al. ${ }^{37}$ observed associations of smoking, hypertension, pulse pressure, diabetes, hypercholesterolemia, body mass index (BMI), and waist-hip ratio, with poorer brain health across grey and white matter macrostructure and microstructure among 9,722 individuals of 44-77 years of age. ${ }^{377}$ Yaffe et al. ${ }^{38)}$ also reported that increased cumulative exposures to hypertension, hyperglycemia, and hypercholesterolemia was associated with worse cognitive dysfunctions.

Since AF patients have a higher risk of dementia, the ability to predict its occurrence in the AF population is critical. A recent study showed that the $\mathrm{CHA}_{2} \mathrm{DS}_{2}$-VASc score was a significant predictor of dementia in AF subjects even after censoring for strokes. ${ }^{11)}$ Therefore, physicians should be vigilant in detecting clinical manifestations that imply potential cognitive decline and functional impairment in AF patients, especially those with a high $\mathrm{CHA}_{2} \mathrm{DS}_{2}$-VASc score. This finding also implies that subclinical strokes and the shared risk factors play significant roles in the development of dementia among patients with AF.

\section{Optimal blood pressure control}

There is accumulating evidence indicating that hypertension in midlife increases the risk of dementia in later life, suggesting it to be a potentially modifiable risk factor. ${ }^{39-41)}$ However, results of randomized clinical trials have generally been inconclusive regarding the effects of blood pressure (BP) reduction on cognitive outcomes in the general population. ${ }^{42-44}$ Since hypertension is common in patients with $\mathrm{AF}$, the population attributable risk and potential healthcare burden are large.2455) High stroke incidence and frequent OAC use in patients with $\mathrm{AF}$ increase the complexity of the relationship between hypertension and dementia risk.

Recently, Kim et al ${ }^{46}$ reported a U-shaped relationship between systolic or diastolic BP and dementia risk in an analysis of 171,228 Korean patients aged 50-69 years, with incidental AF but no existing dementia (Figure 5). A $10 \mathrm{mmHg}$ increase or decrease in the systolic BP, starting from a baseline of $120 \mathrm{mmHg}$, was associated with 4.4\% (95\% CI, 2.7-6.0\%) and $4.6 \%$ ( $95 \%$ CI, 0.1-8.2\%) higher dementia risk, respectively (Figure 5A). An increase or decrease of diastolic BP starting from a baseline of $80 \mathrm{mmHg}$ also increased the dementia risk (Figure 5B). Time-updated regression of the study suggested that the optimal BP range for preventing dementia as 120 to $129 / 80$ to $84 \mathrm{mmHg}$. An increased dementia risk in patients with high BP is present even after censoring for incidental strokes, suggesting that subclinical vascular brain injury including white matter lesions, microbleeds, and covert or microscopic infarcts, might be an important mechanism underlying the relation between hypertension and AF-associated dementia, as suggested in recent studies investigating magnetic resonance imaging of the brain and associated dementia among AF patients. ${ }^{47}$ The authors also reported that hypertension burden (the proportion of days with increased BP during followup) was linearly associated with higher dementia risk (HR, 1.10 per $10 \%$ increase, $95 \% \mathrm{CI}$, 1.08-1.12), suggesting that minimizing the burden of hypertension in AF patients may help to prevent dementia (Figure 6).

\section{Integrated atrial fibrillation management}

Recently published Korean and European AF guidelines advocated the AF Better Care $(\mathrm{ABC})$ pathway for a more integrated approach beyond anticoagulation therapy for patients with AF, with the aim to reduce death and adverse outcomes in $\mathrm{AF} .{ }^{2748)}$ This ABC pathway facilitates care as follows: 'A' Avoid stroke with optimal anticoagulation; 'B' Better symptom 


\section{A Systolic BP and dementia}
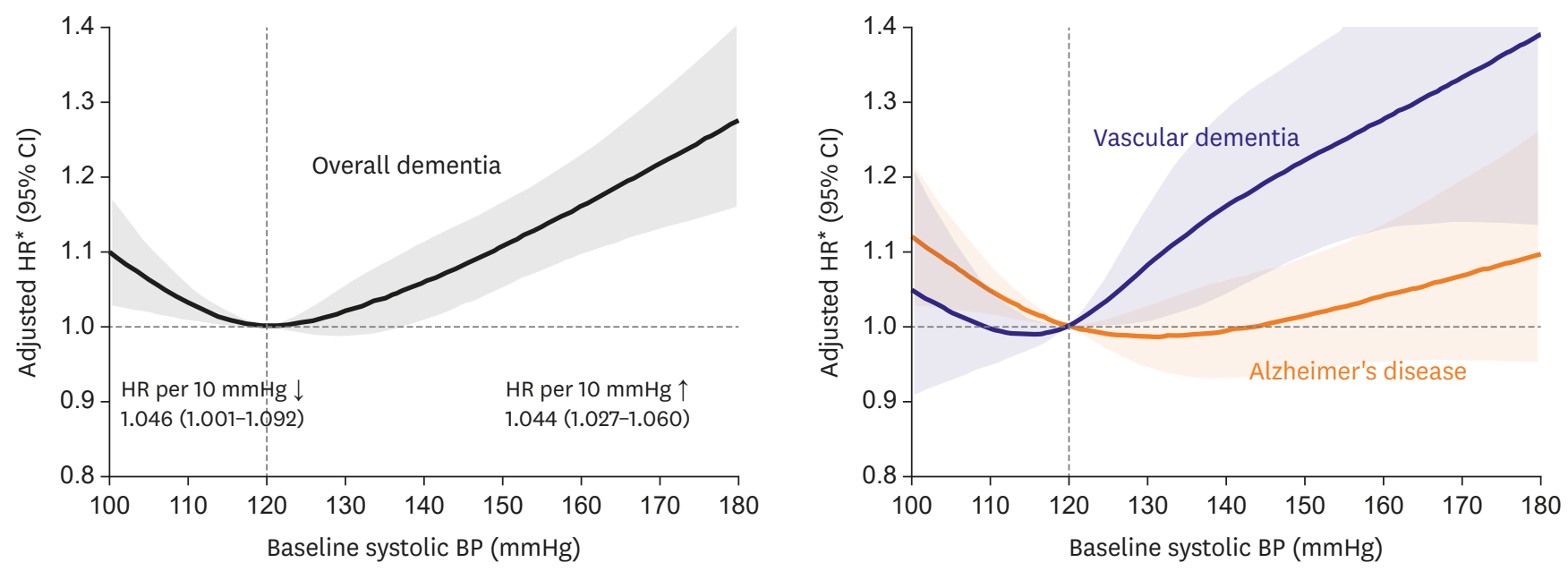

B Diastolic BP and dementia
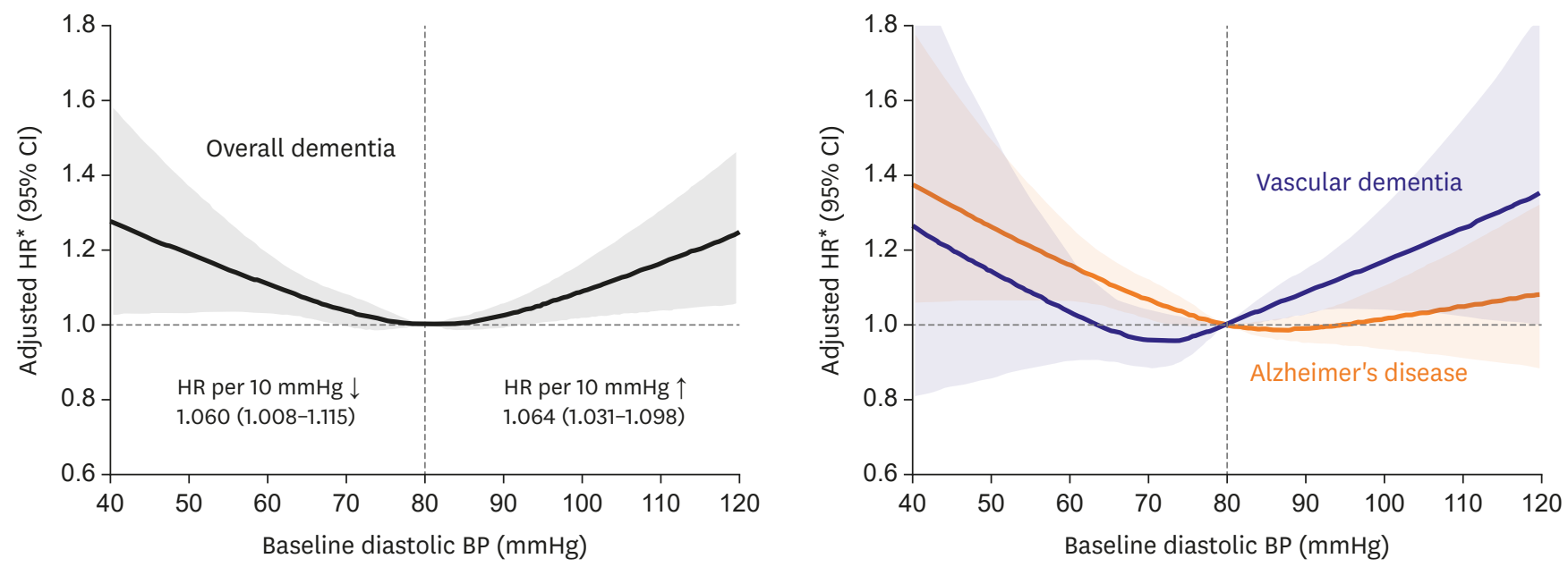

Figure 5. Association of (A) systolic and (B) diastolic BP at baseline with dementia risk. Figure courtesy of Kim et al. ${ }^{46)}$ $\mathrm{BP}=$ blood pressure; $\mathrm{Cl}=$ confidence interval; $\mathrm{HR}$ = hazard ratio.

${ }^{*} \mathrm{HRs}$ were calculated with a systolic or diastolic BP of 120 or $80 \mathrm{mmHg}$ as reference.

management; and 'C' Cardiovascular and comorbidity management. ${ }^{49)}$ Yoon et al. ${ }^{50)}$ previously reported that compliance with the $\mathrm{ABC}$ pathway was associated with improved clinical outcomes in patients with AF. Application of the simple ABC pathway was associated with a lower risk of all causes of death and the composite outcome including all causes of death, ischemic stroke, myocardial infarction, or major bleeding, in patients with $\mathrm{AF}^{50-52)}$

Yang et al..$^{53}$ evaluated whether compliance with the $\mathrm{ABC}$ pathway was associated with a lower risk of dementia. In fact, the $\mathrm{ABC}$ compliant patients with $\mathrm{AF}$ had a lower risk of dementia overall, as well as a reduced risk of Alzheimer's disease and vascular dementia. Since ischemic stroke is closely related to an increased risk of dementia, the reduction of dementia risk in the $\mathrm{ABC}$ group may be related to oral anticoagulation adherence and the control of risk factors. The findings that adherent use of NOAC was associated with a lower risk of ischemic stroke without increasing bleeding risk supports the hypothesized pathway. ${ }^{54)}$ The strong impact of the $\mathrm{ABC}$ pathway on the risk of dementia substantiates and strengthens the concept 

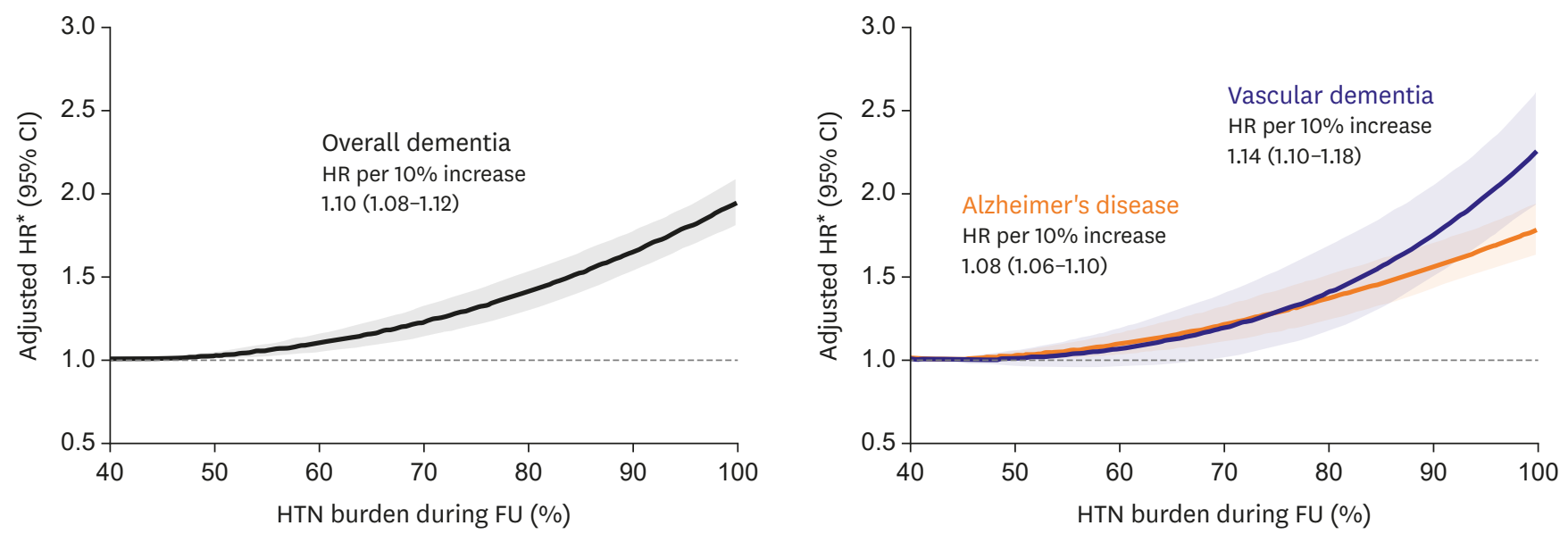

Figure 6. Association of hypertension burden during follow-up with dementia risk. Figure courtesy of Kim et al. ${ }^{46)}$

$\mathrm{Cl}$ = confidence interval; $\mathrm{FU}=$ follow-up; $\mathrm{HR}$ = hazard ratio; $\mathrm{HTN}=$ hypertension.

${ }^{*}$ HRs were calculated with the burden under $40 \%$ as reference.

that a holistic approach for integrated management is associated with a significant clinical benefit for patients with AF.

\section{Other risk factors}

The modification of risk factors (obesity, hypertension, heart failure, diabetes mellitus, and sleep apnea) related to the development and/or progression of AF could delay the onset and progression of cognitive dysfunctions. ${ }^{55) 56}$ In lean Asian populations, prehypertension and impaired fasting glucose were important risk factors of AF, implying that strict blood pressure control and early treatment of diabetes should be emphasized. ${ }^{57)}$ Avoiding abdominal obesity ${ }^{58}$ and weight fluctuation ${ }^{59}$ have been associated with reduced risk of AF development, which possibly reduces or delays the onset and progression of cognitive decline.

Lifestyle behaviors such as smoking, drinking, and physical activity should be monitored in an integrated manner. Alcohol abuse has been associated with an increased risk of dementia (HR, 1.53; 95\% CI, 1.41-1.66) among patients with $\mathrm{AF}$ in an observational cohort study. ${ }^{14}$

\section{CONCLUSIONS}

Incidental $\mathrm{AF}$ was associated with an increased risk of both early- and late-onset dementia, independent of clinical strokes. Younger patients with AF were more prone to the development of dementia than older patients with AF. A higher $\mathrm{CHA}_{2} \mathrm{DS}_{2}$-VASc score was a significant predictor of dementia in patients with $\mathrm{AF}$ even after censoring for strokes. Among patients with $\mathrm{AF}, \mathrm{OAC}$ use was related to a lower incidence of dementia. In particular, NOAC usage was associated with a reduced risk of dementia compared with warfarin. Moreover, successful catheter ablation for AF was associated with a decreased dementia risk. Among midlife AF patients, there were a U-shaped association of $\mathrm{BP}$ and a linear association of hypertension burden with dementia risk. Minimizing the burden of hypertension in patients with AF may help to prevent dementia. Finally, integrated management of AF was associated with a reduced risk of dementia. In sum, due to the high medical burden of AF and dementia, it is necessary to implement integrated AF management to reduce the risk of dementia. 


\section{REFERENCES}

1. Lee H, Kim TH, Baek YS, et al. The trends of atrial fibrillation-related hospital visit and cost, treatment pattern and mortality in Korea: 10-year nationwide sample cohort data. Korean Circ J 2017;47:56-64. PUBMED | CROSSREF

2. Kim D, Yang PS, Jang E, et al. 10-year nationwide trends of the incidence, prevalence, and adverse outcomes of non-valvular atrial fibrillation nationwide health insurance data covering the entire Korean population. Am Heart J2018;202:20-6. PUBMED | CROSSREF

3. Kim D, Yang PS, Jang E, et al. Increasing trends in hospital care burden of atrial fibrillation in Korea, 2006 through 2015. Heart 2018;104:2010-7.

PUBMED | CROSSREF

4. Wortmann M. Dementia: a global health priority - highlights from an ADI and World Health Organization report. Alzheimers Res Ther 2012;4:40. PUBMED | CROSSREF

5. Ott A, Breteler MM, de Bruyne MC, van Harskamp F, Grobbee DE, Hofman A. Atrial fibrillation and dementia in a population-based study. The Rotterdam study. Stroke 1997;28:316-21. PUBMED | CROSSREF

6. Bunch TJ, Weiss JP, Crandall BG, et al. Atrial fibrillation is independently associated with senile, vascular, and Alzheimer's dementia. Heart Rhythm 2010;7:433-7. PUBMED | CROSSREF

7. Dublin S, Anderson ML, Haneuse SJ, et al. Atrial fibrillation and risk of dementia: a prospective cohort study. J Am Geriatr Soc 2011;59:1369-75. PUBMED | CROSSREF

8. Singh-Manoux A, Fayosse A, Sabia S, et al. Atrial fibrillation as a risk factor for cognitive decline and dementia. Eur Heart J 2017;38:2612-8. PUBMED | CROSSREF

9. Marengoni A, Qiu C, Winblad B, Fratiglioni L. Atrial fibrillation, stroke and dementia in the very old: a population-based study. Neurobiol Aging 2011;32:1336-7. PUBMED | CROSSREF

10. Rastas S, Verkkoniemi A, Polvikoski T, et al. Atrial fibrillation, stroke, and cognition: a longitudinal population-based study of people aged 85 and older. Stroke 2007;38:1454-60. PUBMED | CROSSREF

11. Kim D, Yang PS, Yu HT, et al. Risk of dementia in stroke-free patients diagnosed with atrial fibrillation: data from a population-based cohort. Eur Heart J 2019;40:2313-23. PUBMED | CROSSREF

12. Kim D, Yang PS, Lip GY, Joung B. Atrial fibrillation increases the risk of early-onset dementia in the general population: data from a population-based cohort. J Clin Med 2020;9:3665. PUBMED | CROSSREF

13. Chopard R, Piazza G, Gale SA, et al. Dementia and atrial fibrillation: pathophysiological mechanisms and therapeutic implications. Am J Med 2018;131:1408-17. PUBMED | CROSSREF

14. Friberg L, Rosenqvist M. Less dementia with oral anticoagulation in atrial fibrillation. Eur Heart J 2018;39:453-60. PUBMED | CROSSREF

15. Friberg L, Andersson T, Rosenqvist M. Less dementia and stroke in low-risk patients with atrial fibrillation taking oral anticoagulation. Eur Heart J2019;40:2327-35. PUBMED | CROSSREF

16. Jacobs V, Woller SC, Stevens S, et al. Time outside of therapeutic range in atrial fibrillation patients is associated with long-term risk of dementia. Heart Rhythm 2014;11:2206-13. PUBMED | CROSSREF

17. Madhavan M, Hu TY, Gersh BJ, et al. Efficacy of warfarin anticoagulation and incident dementia in a community-based cohort of atrial fibrillation. Mayo Clin Proc 2018;93:145-54. PUBMED | CROSSREF

18. van Norden AG, van den Berg HA, de Laat KF, Gons RA, van Dijk EJ, de Leeuw FE. Frontal and temporal microbleeds are related to cognitive function: the Radboud University Nijmegen Diffusion Tensor and Magnetic Resonance Cohort (RUN DMC) Study. Stroke 2011;42:3382-6. PUBMED | CROSSREF 
19. Ruff CT, Giugliano RP, Braunwald E, et al. Comparison of the efficacy and safety of new oral anticoagulants with warfarin in patients with atrial fibrillation: a meta-analysis of randomised trials. Lancet 2014;383:955-62. PUBMED | CROSSREF

20. Wang KL, Lip GY, Lin SJ, Chiang CE. Non-vitamin K antagonist oral anticoagulants for stroke prevention in Asian patients with nonvalvular atrial fibrillation: meta-analysis. Stroke 2015;46:2555-61. PUBMED | CROSSREF

21. Chen N, Lutsey PL, MacLehose RF, et al. Association of oral anticoagulant type with risk of dementia among patients with nonvalvular atrial fibrillation. J Am Heart Assoc 2018;7:e009561. PUBMED | CROSSREF

22. Jacobs V, May HT, Bair TL, et al. Long-term population-based cerebral ischemic event and cognitive outcomes of direct oral anticoagulants compared with warfarin among long-term anticoagulated patients for atrial fibrillation. Am J Cardiol 2016;118:210-4. PUBMED | CROSSREF

23. Søgaard M, Skjøth F, Jensen M, et al. Nonvitamin K antagonist oral anticoagulants versus warfarin in atrial fibrillation patients and risk of dementia: a nationwide propensity-weighted cohort study. J Am Heart Assoc 2019;8: 011358 PUBMED | CROSSREF

24. Dagres N, Chao TF, Fenelon G, et al. European Heart Rhythm Association (EHRA)/Heart Rhythm Society (HRS)/Asia Pacific Heart Rhythm Society (APHRS)/Latin American Heart Rhythm Society (LAHRS) expert consensus on arrhythmias and cognitive function: what is the best practice? Europace 2018;20:1399-421. PUBMED | CROSSREF

25. Kim D, Yang PS, Jang E, et al. Association of anticoagulant therapy with risk of dementia among patients with atrial fibrillation. Europace 2021;23:184-95. PUBMED | CROSSREF

26. Mark DB, Anstrom KJ, Sheng S, et al. Effect of catheter ablation vs medical therapy on quality of life among patients with atrial fibrillation: the CABANA randomized clinical trial. JAMA 2019;321:1275-85. PUBMED | CROSSREF

27. Hindricks G, Potpara T, Dagres N, et al. 2020 ESC guidelines for the diagnosis and management of atrial fibrillation developed in collaboration with the European Association for Cardio-Thoracic Surgery (EACTS). Eur Heart J 2021;42:373-498. PUBMED | CROSSREF

28. Kirchhof P, Haeusler KG, Blank B, et al. Apixaban in patients at risk of stroke undergoing atrial fibrillation ablation. Eur Heart J 2018;39:2942-55. PUBMED | CROSSREF

29. Jin MN, Kim TH, Kang KW, et al. Atrial fibrillation catheter ablation improves 1-year follow-up cognitive function, especially in patients with impaired cognitive function. Circ Arrhythm Electrophysiol 2019;12:e007197. PUBMED | CROSSREF

30. Haeusler KG, Kirchhof P, Endres M. Left atrial catheter ablation and ischemic stroke. Stroke 2012;43:265-70. PUBMED | CROSSREF

31. Nakamura T, Okishige K, Kanazawa T, et al. Incidence of silent cerebral infarctions after catheter ablation of atrial fibrillation utilizing the second-generation cryoballoon. Europace 2017;19:1681-8. PUBMED | CROSSREF

32. Schwarz N, Kuniss M, Nedelmann M, et al. Neuropsychological decline after catheter ablation of atrial fibrillation. Heart Rhythm 2010;7:1761-7. PUBMED | CROSSREF

33. Deneke T, Jais P, Scaglione M, et al. Silent cerebral events/lesions related to atrial fibrillation ablation: a clinical review. J Cardiovasc Electrophysiol 2015;26:455-63. PUBMED | CROSSREF

34. Kim D, Yang PS, Sung JH, et al. Less dementia after catheter ablation for atrial fibrillation: a nationwide cohort study. Eur Heart J 2020;41:4483-93. PUBMED | CROSSREF

35. Lüscher TF. The heart and the brain: cardiovascular risk factors, atrial fibrillation, and dementia. Eur Heart J2019;40:2271-5. PUBMED | CROSSREF

36. Saliba W, Gronich N, Barnett-Griness O, Rennert G. Usefulness of CHADS 2 and $\mathrm{CHA}_{2} \mathrm{DS}_{2}$-VASc scores in the prediction of new-onset atrial fibrillation: a population-based study. Am J Med 2016;129:843-9. PUBMED | CROSSREF 
37. Cox SR, Lyall DM, Ritchie SJ, et al. Associations between vascular risk factors and brain MRI indices in UK Biobank. Eur Heart J 2019;40:2290-300. PUBMED | CROSSREF

38. Yaffe K, Vittinghoff E, Pletcher MJ, et al. Early adult to midlife cardiovascular risk factors and cognitive function. Circulation 2014;129:1560-7.

PUBMED | CROSSREF

39. Qiu C, Winblad B, Fratiglioni L. The age-dependent relation of blood pressure to cognitive function and dementia. Lancet Neurol 2005;4:487-99. PUBMED | CROSSREF

40. Launer LJ, Ross GW, Petrovitch H, et al. Midlife blood pressure and dementia: the Honolulu-Asia aging study. Neurobiol Aging 2000;21:49-55. PUBMED | CROSSREF

41. Iadecola C, Yaffe $\mathrm{K}$, Biller J, et al. Impact of hypertension on cognitive function: a scientific statement from the American Heart Association. Hypertension 2016;68:e67-94. PUBMED | CROSSREF

42. Rouch L, Cestac P, Hanon O, et al. Antihypertensive drugs, prevention of cognitive decline and dementia: a systematic review of observational studies, randomized controlled trials and meta-analyses, with discussion of potential mechanisms. CNS Drugs 2015;29:113-30. PUBMED | CROSSREF

43. Elias MF, Torres RV, Davey A. Clinical trials of blood pressure lowering and antihypertensive medication: is cognitive measurement state-of-the-art? Am J Hypertens 2018;31:631-42. PUBMED | CROSSREF

44. SPRINT MIND Investigators for the SPRINT Research GroupWilliamson JD, Pajewski NM, et al. Effect of intensive vs standard blood pressure control on probable dementia: a randomized clinical trial. JAMA 2019;321:553-61. PUBMED | CROSSREF

45. Kearney PM, Whelton M, Reynolds K, Muntner P, Whelton PK, He J. Global burden of hypertension: analysis of worldwide data. Lancet 2005;365:217-23. PUBMED | CROSSREF

46. Kim D, Yang PS, Jang E, et al. Blood pressure control and dementia risk in midlife patients with atrial fibrillation. Hypertension 2020;75:1296-304. PUBMED | CROSSREF

47. Conen D, Rodondi N, Müller A, et al. Relationships of overt and silent brain lesions with cognitive function in patients with atrial fibrillation. J Am Coll Cardiol 2019;73:989-99. PUBMED | CROSSREF

48. Joung B, Lee JM, Lee KH, et al. 2018 Korean guideline of atrial fibrillation management. Korean Circ J 2018;48:1033-80. PUBMED | CROSSREF

49. Lip GY. The ABC pathway: an integrated approach to improve AF management. Nat Rev Cardiol 2017;14:627-8. PUBMED | CROSSREF

50. Yoon M, Yang PS, Jang E, et al. Improved population-based clinical outcomes of patients with atrial fibrillation by compliance with the simple ABC (Atrial Fibrillation Better Care) pathway for integrated care management: a nationwide cohort study. Thromb Haemost 2019;119:1695-703. PUBMED | CROSSREF

51. Proietti M, Romiti GF, Olshansky B, Lane DA, Lip GY. Improved outcomes by integrated care of anticoagulated patients with atrial fibrillation using the simple ABC (Atrial Fibrillation Better Care) pathway. Am J Med 2018;131:1359-1366.e6. PUBMED | CROSSREF

52. Pastori D, Pignatelli P, Menichelli D, Violi F, Lip GY. Integrated care management of patients with atrial fibrillation and risk of cardiovascular events: the $\mathrm{ABC}$ (Atrial fibrillation Better Care) pathway in the ATHERO-AF study cohort. Mayo Clin Proc 2019;94:1261-7. PUBMED | CROSSREF

53. Yang PS, Sung JH, Jang E, et al. The effect of integrated care management on dementia in atrial fibrillation. J Clin Med 2020;9:1696. PUBMED | CROSSREF

54. Kim D, Yang PS, Jang E, et al. The optimal drug adherence to maximize the efficacy and safety of nonvitamin K antagonist oral anticoagulant in real-world atrial fibrillation patients. Europace 2020;22:547-57. PUBMED | CROSSREF 
55. Joung B. Risk factor management for atrial fibrillation. Korean Circ J 2019;49:794-807. PUBMED | CROSSREF

56. Gorenek B, Pelliccia A, Benjamin EJ, et al. European Heart Rhythm Association (EHRA)/European Association of Cardiovascular Prevention and Rehabilitation (EACPR) position paper on how to prevent atrial fibrillation endorsed by the Heart Rhythm Society (HRS) and Asia Pacific Heart Rhythm Society (APHRS). Europace 2017;19:190-225.

PUBMED | CROSSREF

57. Lee SS, Ae Kong K, Kim D, et al. Clinical implication of an impaired fasting glucose and prehypertension related to new onset atrial fibrillation in a healthy Asian population without underlying disease: a nationwide cohort study in Korea. Eur Heart J 2017;38:2599-607. PUBMED | CROSSREF

58. Baek YS, Yang PS, Kim TH, et al. Associations of abdominal obesity and new-onset atrial fibrillation in the general population. J Am Heart Assoc 2017;6:e004705.

PUBMED | CROSSREF

59. Lim YM, Yang PS, Jang E, et al. Body mass index variability and long-term risk of new-onset atrial fibrillation in the general population: a Korean nationwide cohort study. Mayo Clin Proc 2019;94:225-35. PUBMED | CROSSREF 